\title{
Inhibition of bacterial undecaprenyl pyrophosphate synthase by small fungal molecules
}

\author{
Junji Inokoshi, Yuichiro Nakamura, Saori Komada, Katsuichiro Komatsu, Hideaki Umeyama and \\ Hiroshi Tomoda
}

Viridicatumtoxin and spirohexaline, small fungal molecules with a tetracyclic scaffold and an additional spirobicyclic ring in common, were found to inhibit bacterial undecaprenyl pyrophosphate (UPP) synthase with IC $_{50}$ values of 4 and $9 \mu \mathrm{M}$, respectively. These molecules showed weak inhibitory activity against catalytically related enzymes such as bacterial octaprenyl pyrophosphate synthase and yeast dehydrodolichyl pyrophosphate synthase, indicating that the compounds preferentially inhibit UPP synthase. They showed antimicrobial activity, particularly against Gram-positive bacteria including methicillin-resistant Staphylococcus aureus (MRSA). Furthermore, molecular modeling strongly suggested that the hydrophobic spirobicyclic ring of viridicatumtoxin interacts with three hydrophobic clefts of the active site in MRSA UPP synthase.

The Journal of Antibiotics (2016) 69, 798-805; doi:10.1038/ja.2016.35; published online 6 April 2016

\section{INTRODUCTION}

Recent increases in antibiotic-resistant pathogenic organisms such as methicillin-resistant Staphylococcus aureus (MRSA), vancomycinresistant Enterococci and multi-drug-resistant Gram-negative bacilli, coupled with the current state of new antibiotics developed by pharmaceutical companies, have created a serious threat to public health. ${ }^{1-3}$ Therefore, there is great demand for the discovery and development of new anti-infective agents possessing a novel mechanism of action and an enhanced antimicrobial profile.

The bacterial cell wall is an attractive target for the development of new antibacterial agents because it is an essential, bacterial-specific structure that is absent in human cells. The biosynthesis of peptidoglycan can be divided into three different stages (Figure 1). ${ }^{4}$ The first stage occurs in the cytoplasm and leads to the synthesis of the nucleotide sugar-linked precursor (UDP-MurNAc-pentapeptide and UDP-GlcNAc). In the second stage, precursor lipid intermediates are synthesized at the cytoplasmic membrane. The phospho-MurNAcpentapeptide moiety of UDP-MurNAc-pentapeptide is transferred to the membrane acceptor bactoprenol, yielding lipid I [MurMAc(pentapeptide)-pyrophosphoryl-undecaprenol]. Then, GlcNAc moiety from UDP-GlcNAc is added to lipid I, yielding lipid II [GlcNAcMurNAc-pentapeptide-pyrophosphoryl-undecaprenol], which is the substrate for the polymerization reaction of the bacterial cell wall. At this stage, the translocation of lipid II from the cytoplasmic side to the outer side of the cytoplasmic membrane occurs. The final stage of peptidoglycan biosynthesis, which takes place at the outer side of the membrane, involves the polymerization of the newly synthesized disaccharide units and incorporation into the growing cell wall peptidoglycan with the penicillin-binding proteins that catalyze the
\end{abstract}

transglycosylation and transpeptidation reactions. All of these stages are potential targets for the development of novel antibiotics.

Undecaprenol, also referred to as a bactoprenol, is a key lipid involved in the biosynthesis of peptidoglycan and a variety of other cell-wall polysaccharide components, such as lipopolysaccharides, the enterobacterial common antigen, capsule polysaccharides, and teichoic acids in certain prokaryotes. In the cell wall biosynthetic pathway, undecaprenyl monophosphate (C55-P) is needed for the synthesis and transport of hydrophilic GlcNAc-MurNAc-pentapeptides across the hydrophobic cytoplasmic membrane to the externally located sites of polymerization (periplasm sites). The precursor for C55-P, undecaprenyl pyrophosphate (UPP), is synthesized by the addition of eight C5 isopentenyl units (cis[Z]-configuration) onto C15-PP (all-trans $[E]$ )-farnesyl pyrophosphate (FPP) (Figure 2). This reaction is catalyzed by UPP synthase (di-trans-poly-cis-decaprenyl cistransferase; EC 2.5.1.31). FPP itself results from head-to-tail condensation of isopentenyl pyrophosphate with dimethylallyl pyrophosphate, generating C10-PP geranyl pyrophosphate, followed by a second condensation of isopentenyl pyrophosphate, a reaction catalyzed by the FPP synthase that is a prototype of the trans-prenyltransferase family. The structure and mixed $E, Z$ stereochemistry of the C55-prenyl product (Figure 2), as deduced from recently obtained knowledge about the reaction mechanism of UPP synthase, confirmed earlier data from MS and NMR spectrometry of the undecaprenol isolated from bacterial membranes. The X-ray crystal structures of several UPP synthases from different species (for example, Escherichia coli, Micrococcus luteus and Helicobacter pylori) reveal a generally conserved architecture. ${ }^{5-7}$ UPP synthase exists as a homo-dimer of identical subunits, each consisting of five conserved regions including isopentenyl 




Figure 1 Cell wall synthesis pathway in bacteria.

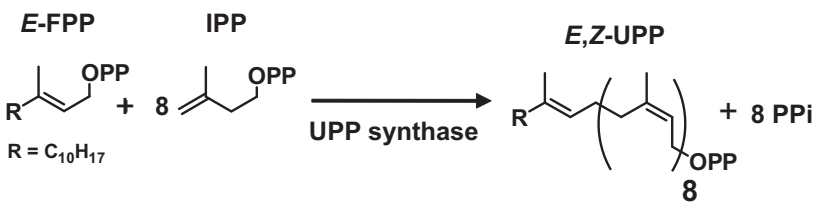

Figure 2 Undecaprenyl pyrophosphate synthase reaction.

pyrophosphate binding, allyic pyrophosphate binding and essential catalytic sites. ${ }^{8}$ Subsequently, a structure-based approach derived from isopentenyl diphosphate ${ }^{9-11}$ and computer-aided drug design ${ }^{7,12-14}$ have been reported. However, their UPP synthase inhibitory activity did not necessarily reflect the antibacterial activity.

In the present study, as part of our interest in discovering natural small molecules that potently and selectively inhibit UPP synthase, we screened about 10000 culture extracts from soil-isolated actinomycetes and fungi for inhibitors of $S$. aureus recombinant UPP synthase activity. Bioactivity-guided fractionation of the active crude extract from the fermentation culture of Penicillium brasilianum FKI-3368 using various chromatographic techniques ${ }^{15}$ led to the discovery of a new compound designated spirohexaline together with known structurally related viridicatumtoxin (Figure 3). Viridicatumtoxin was originally isolated from $P$. viridicatum and showed toxic activity against mice and rats with a single i.p. dose of 80 and $90 \mathrm{mg} \mathrm{kg}^{-1}$, respectively. ${ }^{16-18}$ Recently, viridicatumtoxin B (Figure 3) was reported to show anti-microbial activity against Gram-positive bacteria including MRSA. ${ }^{19,20}$ However, its molecular targets have not been reported. In this study, we reveal that these compounds inhibit the UPP synthase activity of $S$. aureus with anti-MRSA activity.

\section{MATERIALS AND METHODS}

Materials

Viridicatumtoxin and spirohexaline were obtained from a culture broth of $P$. brasilianum FKI-3368. ${ }^{15}\left[1-{ }^{14} \mathrm{C}\right]$ Isopentenyl pyrophosphate (IPP,
$1.48 \mathrm{GBq} \mathrm{mmol}^{-1}$ ) was purchased from PerkinElmer (Waltham, MA, USA). A precoated reversed-phase TLC plate, RP-18, from Merck KGaA (Darmstadt, Germany) was used. Amplex Red was from Invitrogen (Carlsbad, CA, USA). Oligonucleotides were purchased from Operon Biotechnology Co. Ltd. (Tokyo, Japan). IPP, FPP and other biochemical reagents were from Sigma-Aldrich (St Louis, MO, USA) or Wako Pure Chemical Industries, Ltd. (Osaka, Japan).

Bacterial strains, plasmid and enzymes

The E. coli strains used in this study were JM109 (Takara Bio Inc., Shiga, Japan) and BL21(DE3) (Novagen, Abingdon, UK), which were grown in Luria-Bertani (LB) medium (Becton, Dickinson and Company, Franklin Lakes, NJ, USA) with aeration at $37^{\circ} \mathrm{C}$. Saccharomyces cerevisiae OP-3C was as described previously. ${ }^{21}$ Plasmid pET-42b was from Novagen. Inorganic pyrophosphatase, purine nucleoside phosphorylase, xanthine oxidase and horseradish peroxidase were purchased from Sigma-Aldrich. Potato acid phosphatase was purchased from GE Healthcare UK Ltd. (Buckinghamshire, UK). Restriction enzymes and other DNA-modifying enzymes were purchased from New England Biolabs (Beverly, MA, USA) or Takara Bio Inc. and used as described by the manufacturers.

\section{General DNA techniques and transformation}

Chromosomal DNAs of S. aureus and E. coli were prepared using the Qiagen (Hilden, Germany) genomic DNA purification system. To prepare plasmid DNA, a High Pure Plasmid Isolation Kit (Roche Diagnostics GmbH, Mannheim, Germany) was used. Plasmids, PCR products and chromosomal DNA were cleaved with the appropriate restriction enzymes, ligated and transformed into E. coli JM109 cells. Transformed cells were selected on LB agar plates containing kanamycin $\left(30 \mu \mathrm{g} \mathrm{ml}^{-1}\right)$. DNA manipulations in E. coli were performed as described by Sambrook and Russell. ${ }^{22}$

\section{PCR and sequencing}

PCR was carried out using a PCR Thermal Cycler Dice mini (Takara Bio Inc.). Automatic DNA sequencing was carried out using a BigDye Terminator Cycle Sequencing Ready Reaction Kit (Applied Biosystems, Carlsbad, CA, USA) and analyzed on an ABI Prism 3130 Genetic Analyzer (Applied Biosystems). 
<smiles>CCCC(=O)C1=C(O)C[C@@]2(O)[C@H](O)c3c(c(O)c4c(O)cc(OC)c5c4c3C[C@@]5(C)C(C)C)C(=O)[C@@]2(O)C1=O</smiles>

\begin{tabular}{lc}
\hline Compound & $\mathbf{R}$ \\
\hline Viridicatumtoxin (1) & $\mathrm{NH}_{2}$ \\
Spirohexaline (2) & $\mathrm{CH}_{3}$
\end{tabular}

Viridicatumtoxin B<smiles>COc1cc(O)c2c(O)c3c4c(c2c1[C@]1(C3)C(C)=CCC[C@H]1C)C(=O)[C@@]1(O)CC(O)=C(C(N)=O)C(=O)[C@]1(O)C4=O</smiles>

Figure 3 Structures of viridicatumtoxin and spirohexaline.

\section{Constructions of the expression plasmids for UPP synthase and OPP synthase}

UPP synthase gene from $S$. aureus and octaprenyl pyrophosphate (OPP) synthase gene from E. coli were expressed as untagged proteins under the control of the T7 promoter. The full-length genes were amplified by using the following forward and reverse primers: 5'-GCA TAT GTT TAAAAA GC- $3^{\prime}$ and $5^{\prime}$-GGGAAGCTT CTACTCCTCACTC-3' for the UPP synthase gene and 5'-GCA TAT GAA TTT AGA AAA AAT CAA TGA G-3' and 5'-GTG GAA GCT TAA CGA TCGCGT TGAACA G-3' for the OPP synthase gene, respectively. The forward primer used introduced an NdeI site overlapping the potential methionine starting codon and the reverse primer a HindIII site downstream of the stop codon. The PCR products were digested with NdeI and HindIII and cloned in pET-42b digested with NdeI and HindIII.

\section{Overexpression and preparation of UPP synthase and OPP synthase}

The plasmids with correct UPP synthase or OPP synthase gene sequences were transformed into E. coli BL21 (DE-3). As single transformant was grown overnight at $27^{\circ} \mathrm{C}$ in $\mathrm{LB}$ containing kanamycin $\left(30 \mu \mathrm{g} \mathrm{ml} l^{-1}\right)$. The $2 \mathrm{ml}$ overnight cultures were used to inoculate $200 \mathrm{ml}$ of fresh LB medium containing kanamycin $\left(30 \mu \mathrm{g} \mathrm{ml}^{-1}\right)$ and allowed to grow to $\mathrm{OD}_{590}=0.4$ before induction with $1 \mathrm{~mm}$ IPTG (final concentration). The cultures were incubated for $18 \mathrm{~h}$ at $27^{\circ} \mathrm{C}$ and harvested by centrifugation. Cell pellets were frozen and stored at $-70^{\circ} \mathrm{C}$ before use.

Enzyme purification was carried out at $4{ }^{\circ} \mathrm{C}$ or on ice. The cell culture (200 ml) was collected to yield approximately $2 \mathrm{~g}$ of cell paste, which was suspended in $2 \mathrm{ml}$ of lysis buffer containing $100 \mathrm{~mm}$ Tris ( $\mathrm{pH} 7.5$ ) and Complete Protease Inhibitor Cocktail (Roche Diagnostics GmbH). A French pressure cell press apparatus (AIM-AMINCO Spectronic Instruments, Lake Forest, NY, USA) was used to break the cells at 10000 psi. The cell lysate was centrifuged at $100000 \times g$ for $1 \mathrm{~h}$ and the supernatant was used for enzyme sources.

\section{Preparation of microsomal fraction of S. cerevisiae}

Yeast microsomal fraction was used as the source of dehydrodolichyl pyrophosphate (DedolPP) synthase. S. cerevisiae OP-3C was grown at $30^{\circ} \mathrm{C}$ in $100 \mathrm{ml}$ of minimal medium containing $2 \%$ glucose and $0.67 \%$ yeast nitrogen base w/o amino acid (Becton, Dickinson and Company Japan, Tokyo, Japan) and 0.5\% casamino acids (Becton, Dickinson and Company Japan) and 0.04\% adenine until the late logarithmic phase $\left(\mathrm{OD}_{590}\right.$ of 1.5$)$. The cells were harvested by centrifugation at $5000 \mathrm{~g}$ for $10 \mathrm{~min}$, suspended in $10 \mathrm{ml}$ of buffer A containing $10 \mathrm{~mm}$ Tris-HCl (pH 7.5), 1.2 M sorbitol, $1 \mathrm{~mm}$ dithiothreitol, $1 \mathrm{~mm}$ EDTA and $0.5 \mathrm{mg} \mathrm{ml}^{-1}$ zymolyase $100 \mathrm{~T}$ (Seikagaku Corp., Tokyo, Japan) and incubated at $30^{\circ} \mathrm{C}$ for $10 \mathrm{~min}$. The spheroplast-formed cells were collected by centrifugation at $1000 \mathrm{~g}$ for $5 \mathrm{~min}$ and resuspended in $2 \mathrm{ml}$ of buffer B containing $20 \mathrm{~mm}$
Tris- $\mathrm{HCl}$ ( $\mathrm{pH}$ 7.5), $2 \mathrm{~mm} \mathrm{MgCl}_{2}, 1 \mathrm{~mm}$ dithiothreitol and one tablet of Complete Protease Inhibitor Cocktail Tablet (GE Healthcare UK Ltd) per $10 \mathrm{ml}$ and homogenized with a Potter-Elvehjem tissue grinder in an ice-water bath for $30 \mathrm{~s}$. Cell lysates were centrifuged at $12000 \mathrm{~g}$ for $20 \mathrm{~min}$ to remove unbroken cells. Supernatants were further centrifuged at $100000 \mathrm{~g}$ for $1 \mathrm{~h}$ to prepare the microsome-containing fraction.

\section{Assay for UPP synthase and OPP synthase}

UPP synthase reaction was carried out according to the established method with some modification. ${ }^{23}$ Reactions were performed in black 96-well plates from DS Pharma Biomedical Co., Ltd. (Osaka, Japan). The partially purified enzyme fraction containing UPP synthase or OPP synthase was added to the reaction mixture $(100 \mu \mathrm{l})$ containing $100 \mathrm{~mm}$ Tris- $\mathrm{HCl}(\mathrm{pH}$ 7.5), $0.5 \mathrm{~mm}$ $\mathrm{MgCl}_{2}, 50 \mathrm{~mm} \mathrm{KCl}, 3.5 \mu \mathrm{M}$ IPP, $0.5 \mu \mathrm{M}$ FPP, $0.005 \%$ (w/v) Triton X-100 and $5 \mathrm{mU}$ of inorganic pyrophosphatase from $S$. cerevisiae in a total volume of $100 \mu$ l. The reaction was carried out at $37^{\circ} \mathrm{C}$, terminated after $30 \mathrm{~min}$ by the addition of $0.5 \mathrm{M}$ EDTA $(10 \mu \mathrm{l})$ and quenched with a cocktail $(100 \mu \mathrm{l})$ containing $100 \mathrm{~mm}$ Tris- $\mathrm{HCl}$ ( $\mathrm{pH} 7.4$ ), $3 \mathrm{~mm}$ inosine, $0.2 \mathrm{mU} \mathrm{ml}^{-1}$ purine nucleoside phosphorylase, $10 \mathrm{mU} \mathrm{ml}^{-1}$ horseradish peroxidase, $4 \mathrm{mU} \mathrm{ml}^{-1}$ xanthine oxidase and $0.1 \mathrm{~mm}$ Amplex Red. After another 30-min incubation at room temperature, the plate was read at $530 / 590 \mathrm{~nm}$. The amount of phosphate released was calculated from a standard curve prepared with $\mathrm{KH}_{2} \mathrm{PO}_{4}$.

\section{Analysis of products generated by UPP synthase, OPP synthase and DedolPP synthase}

These polyprenyl pyrophosphate (UPP, OPP and DedolPP) synthase activities were measured by determining the amounts of $\left[1-{ }^{14} \mathrm{C}\right] \mathrm{IPP}$ incorporated into butanol-extractable polyprenyl pyrophosphates. ${ }^{24}$ The standard assay was carried out in a reaction mixture $(200 \mu \mathrm{l})$ containing $100 \mathrm{mM}$ Tris- $\mathrm{HCl}$ (pH 7.5), $0.5 \mathrm{~mm} \mathrm{MgCl}_{2}, 10 \mu \mathrm{M}$ FPP, $10 \mu \mathrm{M}\left[1-{ }^{14} \mathrm{C}\right] \mathrm{IPP}$ (37 $\mathrm{MBq} \mathrm{mol}^{-1}$, GE Healthcare, UK Ltd), $0.005 \%$ (w/v) Triton X-100 and a suitable amount of each individual enzyme solution (UPP synthase, OPP synthase or DedolPP synthase). The reaction was initiated by the addition of an enzyme solution. After incubation at $37^{\circ} \mathrm{C}$ for $30 \mathrm{~min}$, the reaction products were extracted with 1-butanol saturated with water and hydrolyzed to the corresponding alcohols with potato acid phosphatase as described by Koyama et al. ${ }^{25}$ The alcohols were extracted with 1-pentane and then developed by reversed-phase TLC (Merck KGaA) with a solvent system of acetone/water (19:1) for UPP synthase and OPP synthase, or acetone/water (39:1) for DedolPP synthase. The TLC plates were exposed to Fuji imaging plates at room temperature for 1day, and then analyzed with an FLA-7000 Bioimage Analyzer (GE Healthcare, UK Ltd).

\section{Homology modeling of UPP synthase and UPP synthase- spirohexaline complexes}

Model structures of UPP synthase were constructed based on the homology modeling method. ${ }^{26-28}$ Reference proteins and sequence alignments were searched using PSI-BLAST. The amino acid sequence of S. aureus UPP synthase (accession no. Q6GHH5_STAAR) was used as a target protein. The X-ray structures of E. coli UPP synthase (PDB code: 1F75_A) were defined and used as a reference protein. The sequence alignments produced by PSI-BLAST were manually adjusted on the biologically important regions and the secondary structure using the CHIMERA modeling system. ${ }^{26,27}$ Then, a homodimer model of UPP synthase-UPP complex was constructed using the computer software FAMS Ligand \& Complex based on these alignments. Docking models of UPP synthase with an inhibitor were simulated using ChooseLD. ${ }^{28}$

\section{Antimicrobial assay}

MIC was determined by the agar dilution method $^{29}$ using Difco Potato Dextrose Agar (Becton, Dickinson and Company Japan) and Difco Mueller Hinton Agar (Becton, Dickinson and Company Japan) for antifungal and antibacterial tests, respectively. Freshly grown cells (or spores) of 16 test microorganisms were inoculated and grown at $25^{\circ} \mathrm{C}$ for fungi and $37^{\circ} \mathrm{C}$ for bacteria. 
Cytotoxic assay

The cytotoxicity of a sample to Jurkat cells was measured by colorimetric assay using 3-(4, 5-dimethylthiazo-2-yl)-2, 5-diphenyltetrazolium bromide (Sigma-Aldrich). ${ }^{30}$ Jurkat cells $\left(5 \times 10^{5}\right.$ cells in $\left.100 \mu \mathrm{l}\right)$ were added to each well of a 96-well microplate. A sample $(1 \mu \mathrm{l}$ in $\mathrm{MeOH})$ was added to each well to make a final concentration of $0-92 \mu \mathrm{M}$. The cells were incubated for $6 \mathrm{~h}$ at $37^{\circ} \mathrm{C}$. 3-(4,5-Dimethylthiazo-2-yl)-2,5-diphenyltetrazolium bromide $\left(10 \mu \mathrm{l}\right.$ of $5.5 \mathrm{mg} \mathrm{ml}^{-1}$ stock solution) and lysis solution ( $90 \mu \mathrm{l}, 40 \% \mathrm{~N}, \mathrm{~N}$-dimethylformamide, $20 \%$ sodium dodecyl sulfate, $2 \%$ acetic acid and $0.03 \% \mathrm{HCl}$ ) were added to each well, and the microplate was shaken for $2 \mathrm{~h}$. The optical density of each well was measured at $540 \mathrm{~nm}$ using a microtiter-plate reader (Elx 808; BioTek Instruments, Winooski, VT, USA).
Other analytical methods

Protein concentration was determined using a BCA protein assay kit (Thermo Fisher Scientific Inc., Waltham, MA, USA).

\section{RESULTS}

Inhibition of UPP synthase by viridicatumtoxin and spirohexaline Viridicatumtoxin and spirohexaline produced by $P$. brasilianum FKI-3368 were discovered as inhibitors of bacterial UPP synthase activity through our screening program. ${ }^{13}$ In this study, the effects of these molecules on the activity of recombinant $S$. aureus UPP synthase were first investigated by an enzyme-coupled fluorescent method. As shown in Figure 4a, they dose-dependently inhibited UPP synthase activity with $\mathrm{IC}_{50}$ values of 4 and $9 \mu \mathrm{M}$, respectively. Next, the effects of
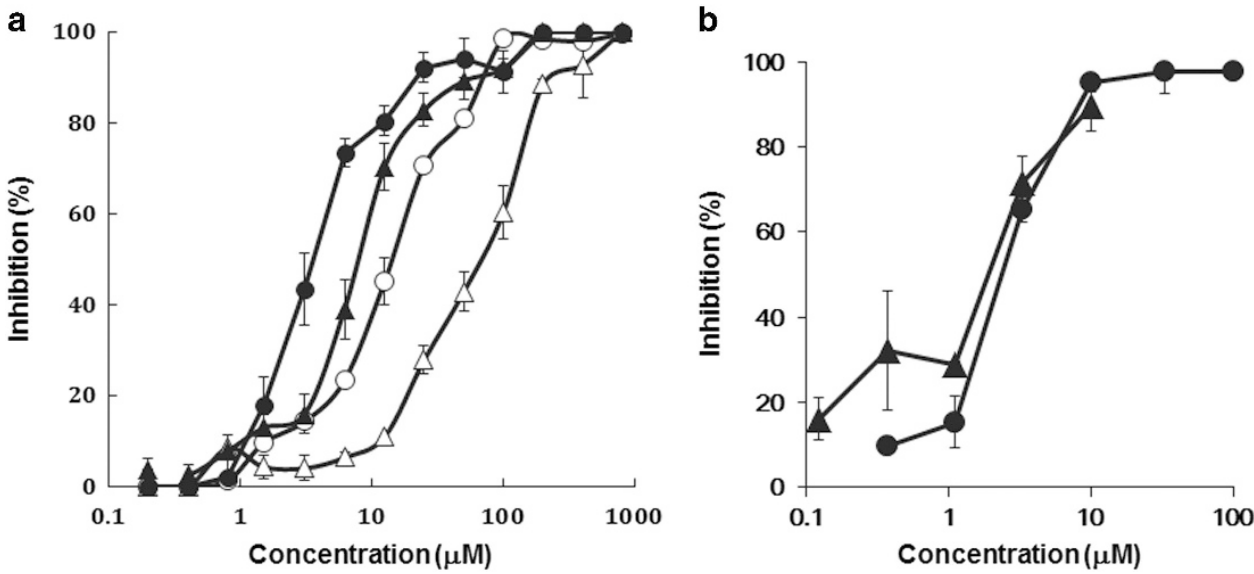

Figure 4 (a) Inhibition of undecaprenyl pyrophosphate synthase and octaprenyl pyrophosphate synthase by viridicatumtoxin and spirohexaline. Closed character, UPP synthase; open character, OPP synthase; circle, viridicatumtoxin; triangle, spirohexaline. (b) Effect of preincubation of UPP synthase activity with viridicatumtoxin. UPP synthase was preincubated with (closed triangle) or without (closed circle) viridicatumtoxin.
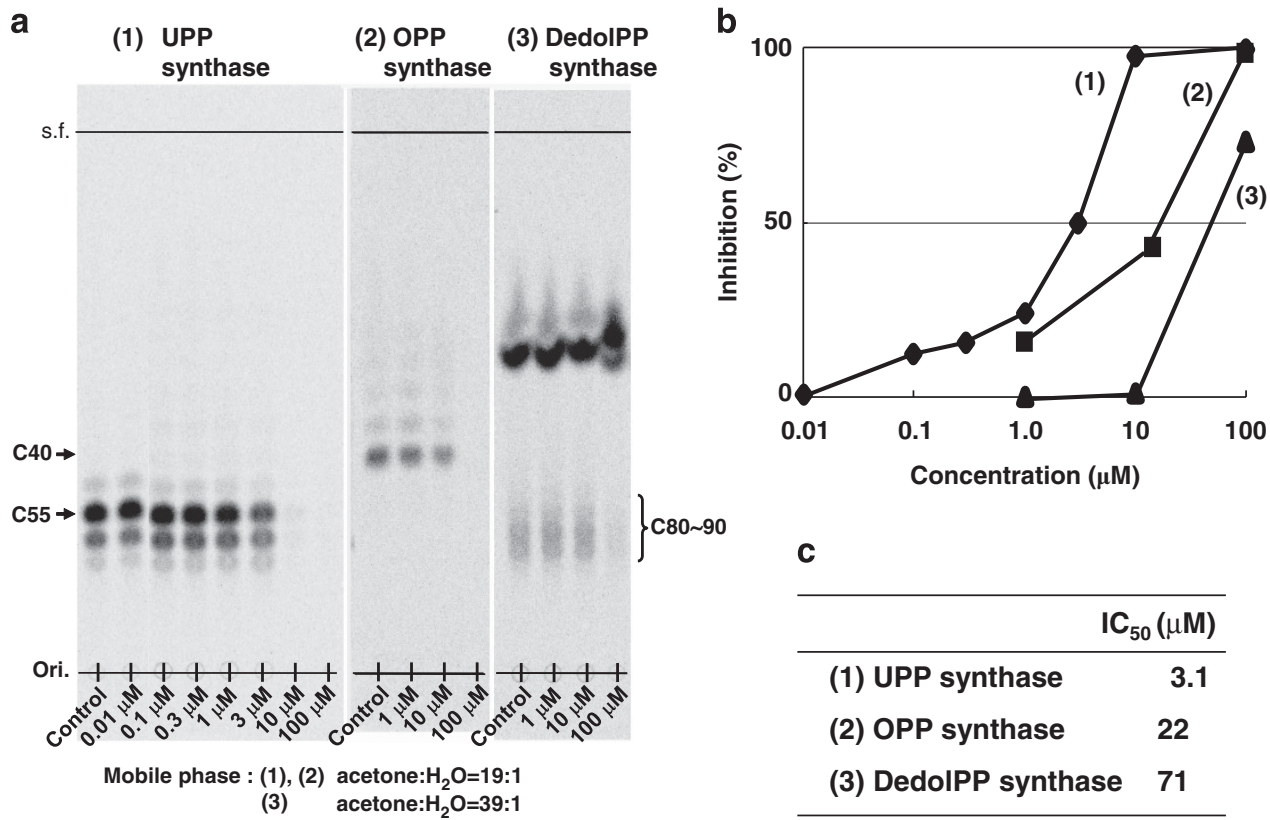

c

\begin{tabular}{lc}
\hline & $I C_{50}(\mu \mathrm{M})$ \\
\hline (1) UPP synthase & 3.1 \\
(2) OPP synthase & 22 \\
(3) DedolPP synthase & 71
\end{tabular}

Figure 5 Effects of viridicatumtoxin on the synthesis of polyprenyl alcohols by UPP synthase, OPP synthase and DeDolPP synthase. (a) Autoradiography after separation of respective prenyl alcohols C55, C40 and C80-90 on THILC by reactions of UPP synthase, OPP synthase and DedoIPP synthase in the presence of viridicatumtoxin $(\mathrm{O}(\mathrm{control})-100 \mu \mathrm{M})$. (b) Inhibition of polyprenyl alcohols production by viridicatumtoxin. From the data (a), inhibition \% (sample product/control product $\times 100$ ) was calculated. (c) $I_{50}$ values for the three enzymes calculated from the data (b). 
the two molecules on E. coli OPP synthase, an analogous enzyme that catalyzes the trans-type condensation reaction of FPP with IPP to generate trans-OPP, was investigated by a similar enzyme-coupled fluorescence assay. Viridicatumtoxin and spirohexaline inhibited OPP synthase activity with higher $\mathrm{IC}_{50}$ values of 16.4 and $64.6 \mu \mathrm{M}$, respectively (Figure $4 \mathrm{a}$ ).

As viridicatumtoxin was more potent than spirohexaline in UPP synthase inhibition, it was selected for further experiments. In order to confirm the potency and selectivity, the amounts of the respective reaction products, $\left[{ }^{14} \mathrm{C}\right] \mathrm{C} 55,\left[{ }^{14} \mathrm{C}\right] \mathrm{C} 40$ and $\left[{ }^{14} \mathrm{C}\right] \mathrm{C} 80-90$ from $\left[{ }^{14} \mathrm{C}\right]$ IPP produced by UPP synthase, OPP synthase and DedolPP synthase, in the presence or absence of viridicatumtoxin, were analyzed by TLC. As shown in Figure $5 \mathrm{a},\left[{ }^{14} \mathrm{C}\right] \mathrm{C} 55$ was detected as a major product by UPP synthase (left column, control). As expected, the radioactivity of $\left[{ }^{14} \mathrm{C}\right] \mathrm{C} 55$ was dose-dependently decreased in the presence of the inhibitor, and completely disappeared at 10 and $100 \mu \mathrm{M}$. The $\mathrm{IC}_{50}$ value was calculated to be $3.1 \mu \mathrm{m}$. On the other hand, OPP synthase, which produced trans-OPP as a major product DedolPP, was inhibited by viridicatumtoxin with $\mathrm{IC}_{50}$ of $21 \mu \mathrm{M}$. Furthermore, DedolPP synthase, which produced dehydrodolichyl pyrophosphate, was inhibited by viridicatumtoxin with an $\mathrm{IC}_{50}$ of $71 \mu \mathrm{m}$. These data indicate that viridicatumtoxin rather selectively inhibited UPP synthase among the catalytically related synthases.

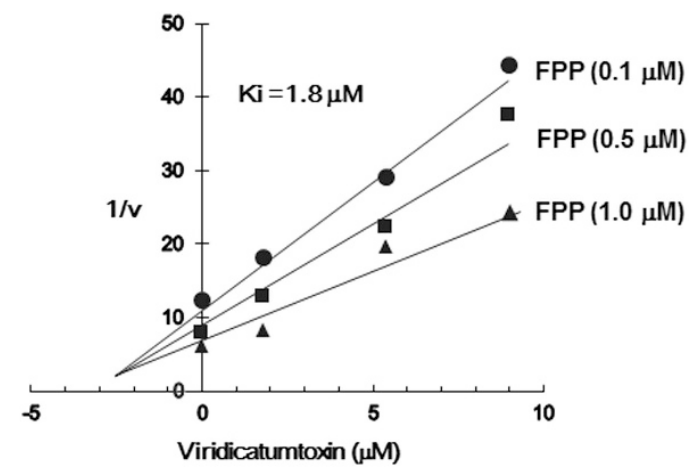

Figure 6 Dixon plot of the inhibition of UPP synthase by viridicatumtoxin.

Table 1 Antimicrobial activities of viridicatumtoxin and spirohexaline

\begin{tabular}{lcc}
\hline & \multicolumn{2}{c}{${\text { MIC }\left(\mu g ~ m l^{-1}\right)}$} \\
\cline { 2 - 3 } Microorganisms & 1 & 2 \\
\hline Staphylococcus aureus ATCC6538p (MSSA) & 0.78 & 1.56 \\
Staphylococcus aureus K24 (MRSA) & 0.78 & 6.25 \\
Bacillus subtilis ATCC6633 & 0.4 & $<0.2$ \\
Micrococcus luteus ATCC9341 & 1.56 & 3.12 \\
Clostridium perfringens ATCC3624 & 0.39 & 1.56 \\
Bacteroides fragilis ATCC23745 & 0.78 & 1.56 \\
Mycobacterium smegmatis ATCC607 & $>100$ & 25 \\
Escherichia coli NIHJ & $>100$ & $>100$ \\
Klebsiella pneumoniae ATCC10031 & $>100$ & $>100$ \\
Pseudomonas aeruginosa IF03080 & $>100$ & $>100$ \\
Serratia marcescens IAM1021 & $>100$ & $>100$ \\
Candida albicans ATCC64550 & 6.2 & 25 \\
Saccharomyces cerevisiae ATCC9763 & 12.5 & 100 \\
Mucor racemosus IF04581 & 25 & 100 \\
Aspergillus niger ATCC9642 & 12.5 & 100 \\
Penicillium chrysogenum IAM12842 & 6.2 & 50 \\
\hline
\end{tabular}

To shed light on the inhibitory mechanism of viridicatumtoxin, UPP synthase was preincubated with several concentrations of viridicatumtoxin $(1,10$ and $100 \mu \mathrm{M})$ for $10 \mathrm{~min}$ at room temperature, and then diluted (final concentrations: $0.1,1$ and $10 \mu \mathrm{M}$, respectively) with the reaction cocktail to start the reaction of UPP synthase. The inhibition curve (Figure $4 \mathrm{~b}$ ) was dependent on the final concentration of the inhibitor, indicating that the UPP synthase was reversibly inhibited by viridicatumtoxin. Furthermore, steady-state kinetic analysis of the inhibitor was carried out (Figure 6). The Dixon plot indicated that viridicatumtoxin inhibits UPP synthase competitively with respect to the substrate FPP, and the inhibitor constant (Ki) value was calculated to be $1.8 \mu \mathrm{M}$.

\section{Antimicrobial activity of viridicatumtoxin and spirohexaline}

The MIC values of the two UPP synthase inhibitors against 16 microorganisms are summarized in Table 1. Viridicatumtoxin and spirohexaline showed very similar antimicrobial spectra. They were active against Gram-positive bacteria, fungi and yeasts. However, viridicatumtoxin was generally more potent than spirohexaline. Importantly, viridicatumtoxin showed the same MIC value of $0.78 \mu \mathrm{g} \mathrm{ml}^{-1}(1.38 \mu \mathrm{M})$ against clinically isolated MRSA and laboratory used MSSA.

The cytotoxic effects of viridicatumtoxin and spirohexaline on Jurkat cells were tested by 3-(4,5-dimethylthiazo-2-yl)-2,5-diphenyltetrazolium bromide assay. Their IC $_{50}$ values were 4.92 and $44.3 \mu \mathrm{M}$, respectively.

\section{Modeling of UPP synthase/viridicatumtoxin complex}

To visualize the complex between UPP synthase and viridicatumtoxin or spirohexaline, a complex model of homodimer UPP synthasesubstrate FPP was constructed using FAMS Ligand Complex, ${ }^{31}$ a fully automated modeling system for protein ligands. Then, docking models of UPP synthase-viridicatumtoxin and UPP synthase-spirohexaline were simulated using ChooseLD. ${ }^{28}$ From the docking model (Figure 7), it was predicted that viridicatumtoxin and spirohexaline bind to the substrate active center of UPP synthase. The docking model indicated that the hydrophobic cyclohexene moieties of viridicatumtoxin and spirohexaline interact with Ile57, Leu95, Phe99 and Phe148, which form the hydrophobic cleft. The hydrophilic 12ketone moieties or $12 \alpha$-hydroxy moieties of viridicatumtoxin and spirohexaline may form a hydrogen bond with Asn35 in the structural P-loop motif, which is the binding region of pyrophosphate of the natural substrate FPP of UPP synthase. Furthermore, the 10-hydroxy moieties of the compounds may form a hydrogen bond with Met54, while 5-hydroxy moieties may form a hydrogen bond with Ala76.

\section{DISCUSSION}

Two small fungal molecules, viridicatumtoxin and spirohexaline, were discovered as inhibitors of bacterial UPP synthase through our screening program. In the present study, their inhibitory activity against catalytically related polyprenyl pyrophosphate synthases (Figures 4 and 5) and their antimicrobial activity (Table 1) were investigated. Some of the data are summarized in Table 2. First, the selectivities of the two molecules in the inhibition of recombinant UPP synthase from $S$. aureus and recombinant OPP synthase from E. coli were compared. From the $\mathrm{IC}_{50}$ values to UPP synthase, it was confirmed that viridicatumtoxin $(4 \mu \mathrm{M})$ is more potent than spirohexaline $(9 \mu \mathrm{M})$. The two molecules also inhibited E. coli OPP synthase with higher $\mathrm{IC}_{50}$ values (16 and $65 \mu \mathrm{M}$, respectively). In terms of the principle of these two enzyme assays, pyrophosphate produced by the enzyme reaction is hydrolyzed by pyrophosphatase to generate 
a

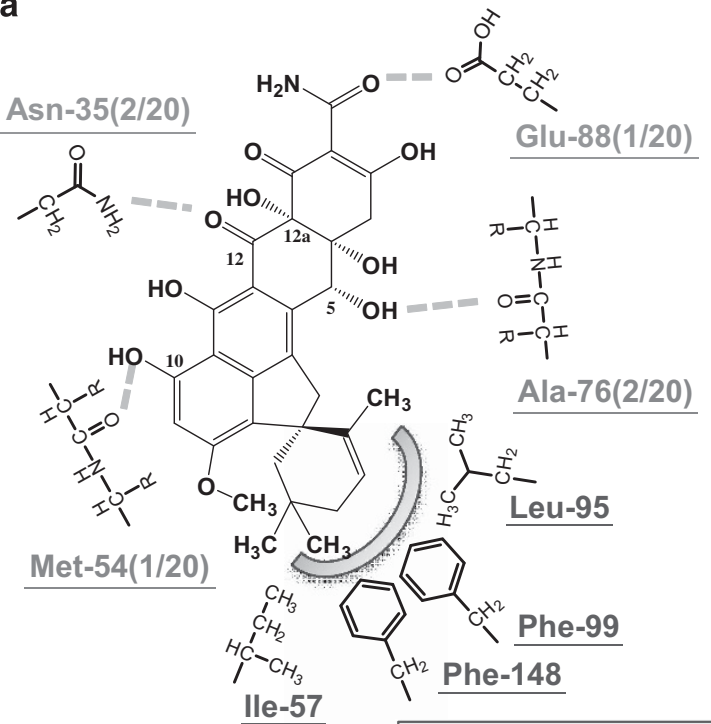

Hydrophobic cleft

b

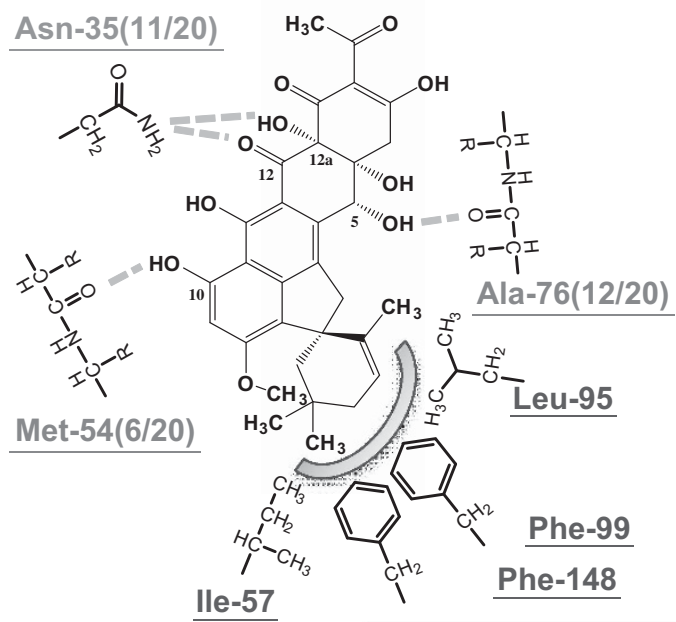

Hydrophobic cleft
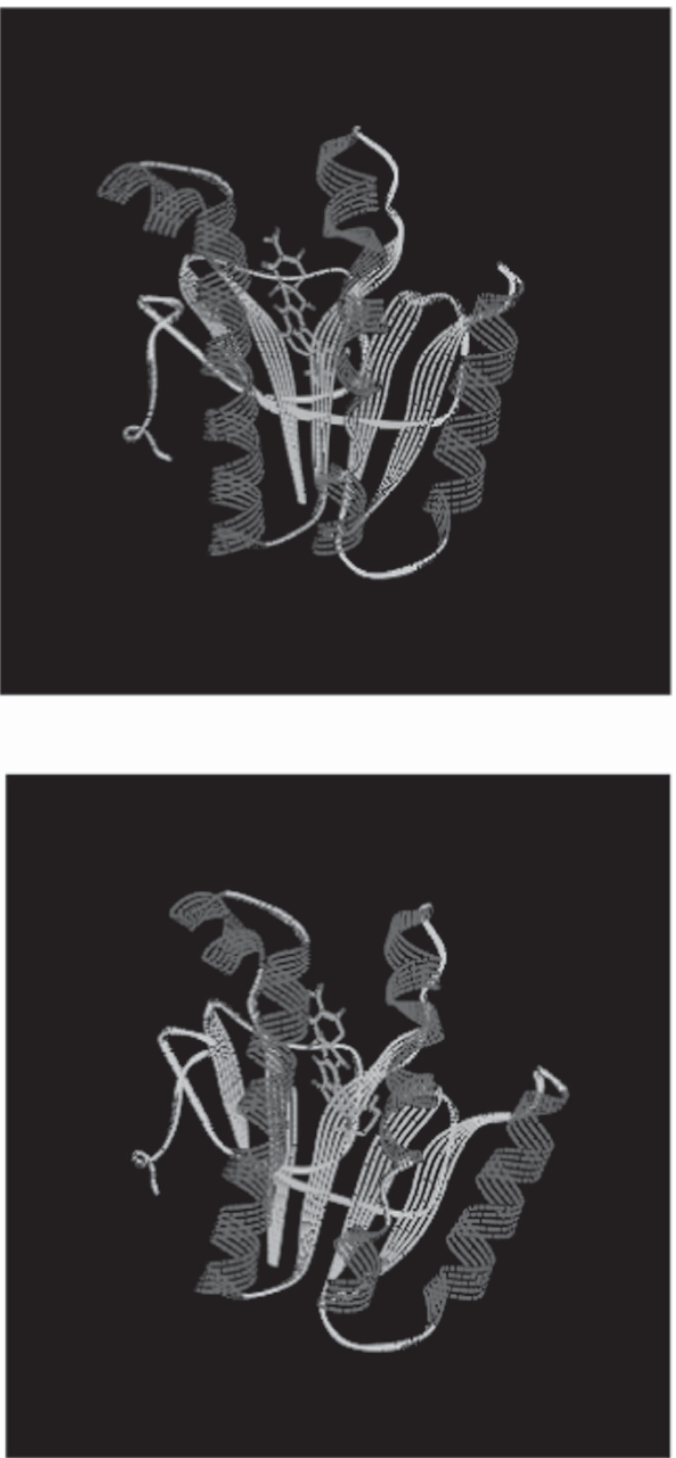

Figure 7 Binding models in the homology model of S. aureus UPP synthase from docking for viridicatumtoxin (a) and spirohexaline (b). A full color version of this figure is available at The Journal of Antibiotics journal online.

phosphate, which is quantified by the enzyme-coupled fluorescent method. The two molecules showed no effect on the pyrophosphatase and the phosphate quantification method. Importantly, the two molecules exhibited anti-S. aureus activity with MIC values of $0.78 \mu \mathrm{g} \mathrm{ml}^{-1}(1.38 \mu \mathrm{M})$ and $1.56 \mu \mathrm{g} \mathrm{ml}^{-1}(2.71 \mu \mathrm{M})$, respectively. These good correlations between UPP synthase inhibition and antiS. aureus activity indicated that inhibition of UPP synthase activity by the molecules caused growth inhibition of $S$. aureus. Viridicatumtoxin and spirohexaline showed no anti-E. coli activity, although they inhibited UPP synthase activity with even higher $\mathrm{IC}_{50}$ values. It might be that the molecules cannot penetrate the porins localizing in the outer membrane of E. coli. To confirm the correlation, the effects of viridicatumtoxin on incorporation of radiolabeled precursors ([methyl $\left.-{ }^{3} \mathrm{H}\right]$ thymidine, [5, 6- $\left.{ }^{3} \mathrm{H}\right]$ uracil, $\left[4, \quad 5-{ }^{3} \mathrm{H}\right] \mathrm{L}$-leucine, and $\left[1-{ }^{3} \mathrm{H}\right] \mathrm{N}$-acetyl-D-glucosamine) into the respective macromolecules (DNA, RNA, protein and peptidoglycan) were investigated. These $\left[{ }^{3} \mathrm{H}\right]$ precursors were added to the middle log-phase of S.aureus $(6 \mathrm{ml})$ in the presence and absence of viridicatumtoxin $(0.9,1.8$ and $5.4 \mu \mathrm{M})$ and incubated at $37^{\circ} \mathrm{C}$ for $1 \mathrm{~h}$. Unfortunately, viridicatumtoxin showed no effects on the synthesis of all the macromolecules. It might be that $1 \mathrm{~h}$ incubation is too short to examine the macromolecule synthesis. C-55P is supplied by two pathways: the de novo pathway from farnesyl-PP and isoprenyl-PP by UPP synthase at the cytosolic side of the plasma membrane, and the UPP recycling pathway by its re-use from the lipid cycle at the outer side of the plasma membrane (Figure 1). Therefore, C-55 P levels might gradually reduce, and it might take a long time to reach the threshold to damage MRSA growth. Otherwise, UPP may play a unknown role in MRSA growth, or an off-target of viridicatumtoxin may be involved. Viridicatumtoxin and spirohexaline showed relatively weak inhibition against yeast DedolPP synthase. Thus, the cytotoxicity of viridicatumtoxin and spirohexaline on Jurkat cells might be due to an off-target effect.

As viridicatumtoxin is a more potent inhibitor than spirohexaline, further study was carried out using this molecule. To confirm the 
Table 2 Summary of biological activity of viridicatumtoxin and spirohexaline

\begin{tabular}{|c|c|c|c|c|}
\hline & & S. aureus & E. coli & S. cerevisiae \\
\hline Compound & Assay & $\begin{array}{c}\text { UPP } \\
\text { synthase }\end{array}$ & $\begin{array}{c}\text { OPP } \\
\text { synthase }\end{array}$ & $\begin{array}{l}\text { DedolPP } \\
\text { synthase }\end{array}$ \\
\hline \multirow[t]{4}{*}{ Viridicatumtoxin } & $\mathrm{IC}_{50}(\mu \mathrm{M})$ & & & \\
\hline & Enzyme & 4.0 & 16 & nt \\
\hline & Product & 3.1 & 21 & 71 \\
\hline & MIC ( $\mu \mathrm{M})$ & 1.38 & $>177$ & 22.1 \\
\hline \multirow[t]{4}{*}{ Spirohexaline } & $\mathrm{IC}_{50}(\mu \mathrm{M})$ & & & \\
\hline & Enzyme & 9.0 & 65 & nt \\
\hline & Product & $\mathrm{nt}$ & nt & $\mathrm{nt}$ \\
\hline & MIC ( $\mu \mathrm{m})$ & 2.71 & $>177$ & 177 \\
\hline
\end{tabular}

selectivity toward UPP synthase activity, the products generated by the three polyprenyl pyrophosphate synthases were analyzed, and the $\mathrm{IC}_{50}$ values are shown in Table 2. By this assay, viridicatumtoxin rather selectively inhibited UPP synthase over OPP synthase of E. coli and DedolPP synthase of $S$. cerevisiae. Considering that viridicatumtoxin showed anti-S. cerevisiae activity, these data appeared reasonable to explain the viridicatumtoxin action.

As a key tool in structural molecular biology, a molecular docking approach was applied to propose a working hypothesis of the inhibitory mechanism between the two inhibitors and bacterial UPP synthase. The crystallographic structures of UPP synthase from E. coli, ${ }^{6}$ M. luteus ${ }^{5}$ and $H$. pyroli ${ }^{7}$ were reported. On the basis of the sequence alignments between E. coli UPP synthase and S. aureus UPP synthase, the 3D structural model was constructed using the homology modeling program FAMS, ${ }^{31}$ and then the docking models of UPP synthase-viridicatumtoxin/spirohexaline were constructed using ChooseLD. ${ }^{28}$ As shown in Figure 6, viridicatumtoxin and spirohexaline were well fitted into a large cleft on the molecular surface of UPP synthase. An overall model for the substrate binding sites and catalytic center in M. luteus BP 26 UPP synthase ${ }^{8}$ has been proposed. This model indicates a critical function of the structural P-loop motif as well as Asp29 and Arg33 in the binding of pyrophosphate moiety of the natural substrate FPP. The co-crystal structure of E. coli UPP synthase with FPP in the active site of the enzyme showed that the pyrophosphate head of FPP is bound to the backbone imine moiety of Gly29 and Arg30 as well as the side chains of Asn28, Arg30 and Arg39 through hydrogen bonding and that the hydrocarbon moiety of FPP interacts with the side chains of hydrophobic amino acids, Leu85, Leu88 and Phe89, which form the hydrophobic cleft. ${ }^{32}$ Viridicatumtoxin and spirohexaline have similar distributions of the amphipathic polarity with FPP; the cyclohexene moiety of the compounds is hydrophobic and the naphthacene skeleton of the compounds is hydrophilic. The docking models of $S$. aureus UPP synthase and viridicatumtoxin/spirohexaline indicated that the $12 \alpha$-hydroxy moiety of the compounds is bound to Asn35 in a P-loop via hydrogen bonding and the hydrophobic cyclohexene moiety interacts with Ile57, Leu95, Phe99 and Phe148 on the hydrophobic cleft region. Among them, Leu95 and Phe99 in S. aureus UPP synthase correspond to Leu91 and Phe95 in M. luteus UPP synthase and Leu85 and Phe89 in E. coli UPP synthase, indicating that these compounds compete with FPP at the FPP binding site. The steady-state kinetics also supported this hypothesis. Thus, viridicatumtoxin and spirohexaline bind to the active center of UPP synthase and hinder the formation of UPP synthase-IPP intermediate.

Recently, UPP synthase has been recognized as a potential target for the development of new antimicrobial agents. Accordingly, several screening systems have been developed to search for new UPP synthase inhibitors: enzyme-based assays by measuring the amounts of phosphate released in the enzyme reaction, ${ }^{15}$ as our group utilized; cell-based assays by measuring $\left[{ }^{14} \mathrm{C}\right] \mathrm{UPP}$ generated from $\left[{ }^{14} \mathrm{C}\right] \mathrm{IPP}$ by the enzyme; and in silico virtual assays in which pharmacophore models are applied from the co-crystal structural data between UPP synthase and the substrate IPP. As a result, a number of inhibitors were successfully discovered using UPP synthase of E. coli, ${ }^{10}$ S. pneumonia, ${ }^{11,14}$ H. pylori ${ }^{7}$ and $S$. aureus $^{12}$ as an enzyme source. Among them, however, only a few compounds such as tetramic acid derivative $4 a,{ }^{11}$ spirohexaline, ${ }^{15}$ viridicatumtoxin, ${ }^{15}$ epi-trichosetin, ${ }^{33}$ biphenyl compound $^{13}$ and isoxazole compound ${ }^{14}$ were reported to show antimicrobial activity due to the inhibition of UPP synthase, while a number of inhibitors exhibited no antimicrobial activity. In particular, a biphenyl compound is the most potent inhibitor of MRSA UPP synthase ( $\mathrm{IC}_{50}$ $\sim 100 \mathrm{nM}$ ) with growth inhibitors of MRSA. ${ }^{13}$

In conclusion, the present work clarified the inhibitory mechanism of viridicatumtoxin and spirohexaline with UPP synthase. Further discovery of more potent inhibitors is expected.

\section{CONFLICT OF INTEREST}

The authors declare no conflict of interest.

\section{ACKNOWLEDGEMENTS}

This work was supported by a Grant-in-Aid for Scientific Research on Scientific Research (B) 18390008 (to HT) from the Ministry of Education, Culture, Sports, Science and Technology, Japan.

1 Rybak, M. J. Resistance to antimicrobial agents: an update. Pharmacotherapy 24, 203S-215S (2004).

2 Silver, L. L. \& Bostian, K. A. Discovery and development of new antibiotics: the problem of antibiotic resistance. Antimicrob. Agents Chemother. 37, 377-383 (1993).

3 Yoneyama, H. \& Katsumata, R. R. Antibiotic resistance in bacteria and its future for novel antibiotic development. Biosci. Biotechnol. Biochem. 70, 1060-1075 (2006).

4 Walsh, C. Antibiotics That Act on Cell Wall Biosynthesis in Antibiotics Actions, Origins, Resistance (ed. Walsh, C.) 23-36 (ASM Press, Washington, DC, USA, 2003).

5 Fujihashi, M. et al. Crystal structure of cis-prenyl chain elongating enzyme, undecaprenyl diphosphate synthase. Proc. Natl Acad. Sci. USA 98, 4337-4342 (2001).

6 Guo, R. T. et al. Crystal structures of undecaprenyl pyrophosphate synthase in complex with magnesium, isopentenyl pyrophosphate, and farnesyl thiopyrophosphate: roles of the metal ion and conserved residues in catalysis. J. Biol. Chem. 280, 20762-70774 (2005).

7 Kuo, C. J. et al. Structure-based inhibitors exhibit differential activities against Helicobacter pylori and Escherichia coli undecaprenyl pyrophosphate synthases. J. Biomed. Biotechnol. 2008, 841312 (2008).

8 Takahashi, S. \& Koyama, T. Structure and function of cis-prenyl chain elongating enzymes. Chem. Rec. 6, 194-205 (2006).

9 Scholte, A. A., Eubanks, L. M., Poulter, C. D. \& Vederas, J. C. Synthesis and biological activity of isopentenyl diphosphate analogues. Bioorg. Med. Chem. 12, 763-770 (2004).

10 Guo, R. T. et al. Bisphosphonates target multiple sites in both cis- and trans- prenyltransferases. Proc. Natl Acad. Sci. USA 104, 10022-10027 (2007).

11 Peukert, S. et al. Design and structure-activity relationships of potent and selective inhibitors of undecaprenyl pyrophosphate synthase (UPPS): tetramic, tetronic acids and dihydropyridin-2-ones. Bioorg. Med. Chem. Lett. 18, 1840-1844 (2008).

12 Durrant, J. D. et al. Non-bisphosphonate inhibitors of isoprenoid biosynthesis identified via computer-aided drug design. Chem. Biol. Drug Des. 78, 323-332 (2011).

13 Zhu, W. et al. Antibacterial drug leads targeting isoprenoid biosynthesis. Proc. Natl Acad. Sci. USA 110, 123-128 (2013).

14 Danley, D. E. et al. Discovery and structural characterization of an allosteric inhibitor of bacterial cis-prenyltransferase. Protein Sci. 24, 20-26 (2015).

15 Inokoshi, J. et al. Spirohexalines, new inhibitors of bacterial undecaprenyl pyrophosphate synthase, produced by Penicillium brasilianum FKI-3368. J. Antibiot. 66, 37-41 (2013). 
16 Hutchison, R. D., Steyn, P. S. \& Van Rensburg, S. J. Viridicatumtoxin, a new mycotoxin from Penicillium viridicatum Westling. Toxicol. Appl. Pharmacol. 24, 507-509 (1973).

17 Jesus, A. E., Hull, W. E., Steyn, P. S., Heerden, F. R. \& Vleggaar, R. Biosynthesis of viridicatumtoxin, a mycotoxin from Penicilium expansum. J. Chem. Soc. Chem. Commun. 1982, 902-904 (1982).

18 Kabuto, C. et al. X-Ray structure of viridicatumtoxin: a new class of mycotoxin from Penicillium viridicatum westling. J. Chem. Soc. Chem. Commun. 1976, 728-729 (1976).

19 Zheng, C. J., Yu, H. E., Kim, E. H. \& Kim, W. G. Viridicatumtoxin B, a new anti-MRSA agent from Penicillium sp. FR11. J. Antibiot. 61, 633-637 (2008).

20 Nicolaou, K. C. et al. Total synthesis and structural revision of viridicatumtoxin B. Angew. Chem. Int. Ed. Engl. 52, 8736-8741 (2013).

21 Inokoshi, J. et al. Cerulenin-resistant mutants of Saccharomyces cerevisiae with an altered fatty acid synthase gene. Mol. Gen. Genet. 244, 90-96 (1994).

22 Sambrook, J. \& Russell, D. W. Molecular Cloning: A Laboratory Manual 3rd edn. (Cold Spring Harbor Laboratory Press, NY, USA, 2001).

23 Vazquez, M. J., Rodriguez, B., Zapatero, C. \& Tew, D.G. Determination of phosphate in nanomolar range by an enzyme-coupling fluorescent method. Anal. Biochem. 320, 292-298 (2003).

24 Kharel, Y., Zhang, Y. W., Fujihashi, M., Miki, K. \& Koyama, T. Significance of highly conserved aromatic residues in Micrococcus luteus BP 26 undecaprenyl pyrophosphate synthase. J. Biochem. 134, 819-826 (2003)
25 Koyama, T., Fujii, H. \& Ogura, K. Enzymatic hydrolysis of polyprenyl pyrophosphates. Methods Enzymol. 110, 153-155 (1985).

26 Yoneda, T., Komooka, H. \& Umeyama, H. A computer modeling study of the interaction between tissue factor pathway inhibitor and blood coagulation factor Xa. J. Protein Chem. 16, 597-605 (1997).

27 Takeda-Shitaka, M. \& Umeyama, H. Elucidation of the cause for reduced activity of abnormal human plasmin containing an Ala55-Thr mutation: importance of highly conserved Ala55 in serine proteases. FEBS Lett. 425, 448-452 (1998).

28 Takaya, D. et al. Bioinformatics based ligand-docking and in-silico screening. Chem. Pharm. Bull 56, 742-744 (2008).

29 Nagayama, A. et al. Final report from the Committee on Antimicrobial Susceptibility Testing, Japanese Society of Chemotherapy, on the agar dilution method (2007). J. Infec. Chemother 14, 383-392 (2008).

30 Mosmann, T. Rapid colorimetric assay for cellular growth and survival: application to proliferation and cytotoxicity assays. J. Immunol. Methods 65, 55-63 (1983).

31 Takeda-Shitaka, M., Takaya, D., Chiba, C., Tanaka, H. \& Umeyama, H. Protein structure prediction in structure based drug design. Curr. Med. Chem. 11, 551-558 (2004).

32 Chang, S. Y., Ko, T. P., Chen, A. P. C., Wang, A. H. J. \& Liang, P. H. Substrate binding mode and reaction mechanism of undecaprenyl pyrophosphate synthase deduced from crystallographic studies. Protein Sci. 13, 971-978 (2004).

33 Inokoshi, J. et al. Epi-trichosetin, a new undecaprenyl pyrophosphate synthase inhibitor, produced by Fusarium oxysporum FKI-4553. J. Antibiot. 66, 549-554 (2013). 